\title{
Divulgación PPDQ
}

\section{El café con aroma a nuestra cultura. La química de la bebida nacional}

\section{Rodrigo Rodríguez Cepeda ${ }^{1}$ \\ Breve historia del café en Colombia}

Para hablar de café en Colombia es necesario remontarse a 1732, cuando (se cree comúnmente) los jesuitas fueron los primeros cultivadores del grano en Colombia, en la región del Orinoco. Se cree que el párroco de Salazar de las Palmas, Francisco Romero, impuso como penitencia a sus feligreses la siembra de cafetos para perdonar sus culpas; el método fue tan exitoso que otros párrocos siguieron su ejemplo, expandiendo así la siembra de café (Echeverri, Buitrago, Montes, Mejía y González, 2005). Posteriormente, en 1840, se establecen las primeras grandes haciendas cafeteras en Santander, y la producción se amplía a Cundinamarca y Tolima (1870), de esta manera, en 1874, el 90 \% de la producción se centraba en Santander. Para el caso de Antioquia, hacia 1890, las familias Ospina, Jaramillo y Vásquez establecieron grandes cafetales con la última tecnología conocida en el momento; posteriormente, otros ricos hacendados establecen cultivos en Fredonia donde rápidamente se convierte en el centro de la producción cafetera antioqueña, favoreciendo una rápida colonización del grano en las tierras del sur (viejo Caldas), hasta el valle del Cauca, todo ello gracias a los buenos precios de venta en Nueva York.

Ya en el siglo XX, una vez terminada la guerra de los Mil Días en 1902, se abrió la posibilidad de ampliar aún más la siembra del café en tierras muy fértiles, antes inexplotadas como Filandia, Calarcá, Montenegro, Circasia, Pijao y Génova en el departamento del Quindío (Valencia, Rojas, \& Beltrán, 2015). El año 1927 marca un punto de referencia importante en el desarrollo del café como industria, ya que un grupo de caficultores se reúne y funda la Federación Nacional de Cafeteros, con el fin de fortalecer la industria cafetera en el país, y probablemente, sin ser la

1 Químico MSc.; MBA.; D.E. Profesor Departamento de Química, Universidad Pedagógica Nacional. 
principal intención, se fortalece la ciencia en el país gracias a que en 1938 se creó Cenicafe, un instituto dedicado a la investigación científica. Esta entidad ha permitido desarrollar mejores variedades de café, así como prácticas agrícolas amigables con el medio ambiente.

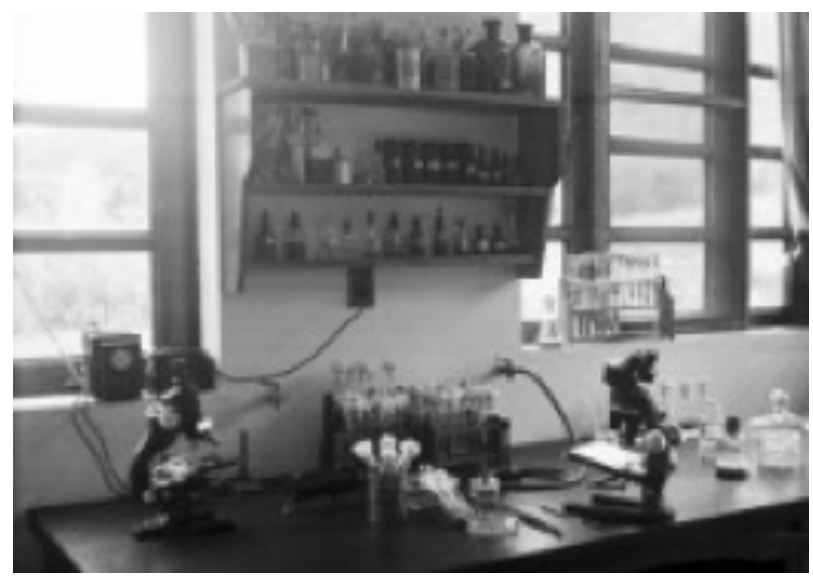

Figura 1. Laboratorio Cenicafe

Fuente: Cenicafe, s.f.

En este contexto, cuando tomamos una taza de café no solamente consumimos una bebida estimulante, sino que estamos apoyando a más de un millón de personas que se emplean en este sector agrícola (Echeverri, Buitrago, Montes, Mejía y González, 2005), que pertenecen a familias que históricamente han vivido del cultivo de este grano y han sido el soporte económico del país. A su vez, cada taza de café que se consume aporta en el desarrollo científico del país a través de Cenicafe.

\section{La química de la taza de café}

Al consumir una taza de café, un festín químico llega a los sentidos gracias a las características químicas de la almendra, constituida principalmente por carbohidratos, lípidos, proteínas, alcaloides como la cafeína y la trigonelina, así como ácidos carboxílicos, fenólicos y diversos compuestos volátiles. Estos le dan a la bebida características sensoriales especiales, las cuales marcan las diversas calidades del café y, por lo tanto, el precio en el mercado.

Para logar una buena taza de café es necesario realizar varios procesos, en los cuales la química toma importancia. Las características químicas dependen de diversas variables, entre las que se destacan: la variedad del grano, el grado de madurez de la almendra, la fermentación, el secado, el almacenamiento, el proceso de la tostación y hasta la preparación, aspectos que condicionan sensaciones como la acidez, el amargo, el cuerpo, el dulzor y el aroma (Puerta , 2011). En la figura 2 se puede observar la composición química típica de una taza de café, preparada con la variedad arábica.
Café preparación:

7 gr. de Café Arábica

$100 \mathrm{ml}$. de agua

Composición:

Agua 98,75\%, ácido clorogénico 100 mg., ácido químico 40 mg., ácido cítrico 60 mg., ácido acético 35 mg., ácido málico 20 mg., ácido fosfórico $15 \mathrm{mg}$., ácido láctico $10 \mathrm{mg}$., ácido nicotínico 1 mg., otros ácidos 30 mg., cafeína 90 mg., azúcares reductores 19 mg., polisacáridos 236 mg., melanoidinas 272,8 mg., péptidos $75 \mathrm{mg}$., potasio $105 \mathrm{mg}$., otros minerales $140 \mathrm{mg}$.

\section{Volátiles de olor dulce, tostado, frutal, ahumado:}

4-hidroxi-2,5-dimetil-3(2H)-furanona, 5etil-4hdroxi-2metil-3(2H) furona, 4-etil-2,3-butanodiona, 4 vinilguaiacol, guayacol, 4-etilguayacol, sotolona, eugenol, metional, 2-pentanona, (E)- $\beta$-damascenona, 4-metil-2,3-pentanodiona, 2,3-hexanodiona, 5-etil-3-hidroxi-4metil-2(5H)-furanona, 2-metilbutanal, 3-mercapto-3metil-butilformato, acetaldehido y otros 800 compuestos
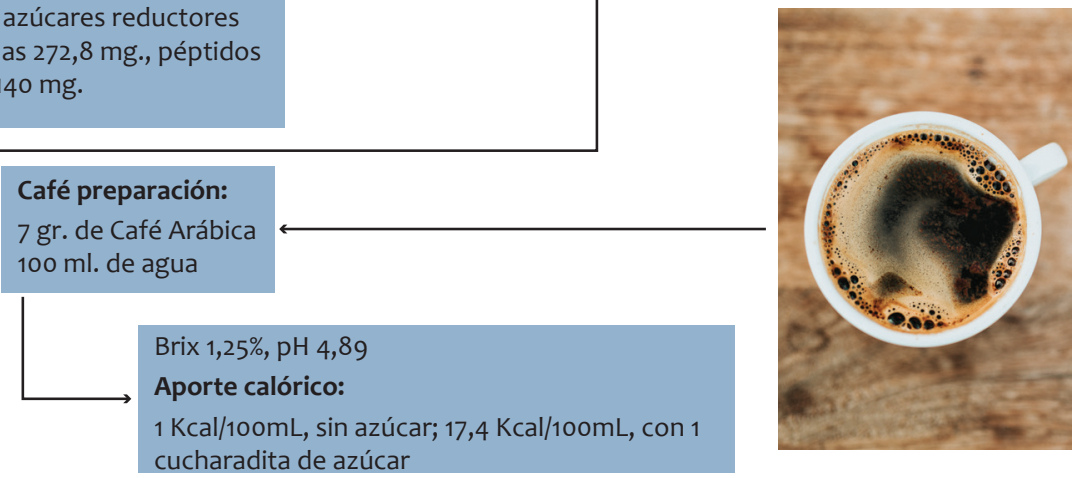

Figura 2. Composición química de una taza de café Fuente: Puerta (2011). 
Tabla 1. Concentración de fenoles y cafeína

\begin{tabular}{|c|c|c|c|c|}
\hline Compuesto & Tostado ligero & Tostado medio & Tostado alto & Tostado oscuro \\
\hline Fenoles $\mathrm{mg} / \mathrm{g}$ & $83,60-134,07$ & - & - & $102,41-115,45$ \\
\hline Cafeína $\mathrm{mg} / \mathrm{g}$ & $30,72-39,28$ & $32,05-40,06$ & $33,26-39,58$ & $31,82-37,39$ \\
\hline
\end{tabular}

Fuente: Lazcano, Trejo, Pascual y Vargas (2016).

\section{Química del proceso de torrefacción}

Algunos investigadores han trabajado sobre las reacciones y los cambios químicos que se producen en grano de café durante el proceso de tostación o torrefacción. Una de las grandes preocupaciones es la posible disminución de compuestos fenólicos, a los cuales se les reconoce su gran actividad antioxidante, y que por efectos térmicos se pueden degradar. Sin embargo, también se ha planteado que los procesos térmicos pueden generar compuestos químicos con actividad antioxidante derivados de la reacción de Maillard, especialmente las melanoidinas. Pérez-Hérnandez, Chávez-Quiroz, Medina-Juárez y Gámez-Meza (2016) determinaron y cuantificaron compuestos fenólicos, así como el contenido de melanoidinas en dos variedades de café verde y procesados: café arábica (coffea arabica) y café soluble de grano robusto (coffea canephora, sin. Coffea robusta). En este estudio determinaron una mayor actividad antioxidante en los granos procesados que en los verdes, con una disminución en los compuestos fenólicos, especialmente en la variedad robusta, determinados mediante HPLC.

Otras investigaciones han demostrado que el contenido de cafeína aumenta con el nivel de tostado del grano, y la concentración de fenoles disminuye (tabla 1), haciendo evidentes los cambios que sufre el grano con este proceso.

Igualmente, se ha verificado que el proceso de torrefacción no solamente afecta la concentración de fenoles y cafeína, sino que también permite la formación de compuestos volátiles y sustancias responsables del sabor. En la tabla 2 se relacionan algunos de los compuestos químicos producidos en la tostación del grano, responsables del aroma.
Tabla 2. Compuestos químicos y aroma del café

\begin{tabular}{|c|c|}
\hline $\begin{array}{c}\text { Grupo de compuestos } \\
\text { químicos }\end{array}$ & Aroma en el grano tostado \\
\hline Piridinas & $\begin{array}{c}\text { Hierbas verdes, tabaco, } \\
\text { astringente, tierra }\end{array}$ \\
\hline Furanos & $\begin{array}{c}\text { Chocolate, quemado, tierra, } \\
\text { herbal, madera, caramelo }\end{array}$ \\
\hline Aminas & Picante \\
\hline Pirazinas & Arveja, pimiento \\
\hline Aldehidos & $\begin{array}{l}\text { Madera, pepino, grasa frita, } \\
\text { rosa, miel, jacinto. }\end{array}$ \\
\hline Cetonas & Fruta cocinada, rosas \\
\hline Alcoholes & Floral, cítrico \\
\hline Ácidos & Queso, acre \\
\hline
\end{tabular}

Fuente: Puerta (2011).

Con respecto al atributo de sabor, el proceso de torrefacción permite que se desarrollen diversas reacciones, entre los productos más importantes son, en su mayoría, los ácidos relacionados en la tabla 3.

Tabla 3. Compuestos químicos responsables del sabor

\begin{tabular}{|c|c|}
\hline Ácido & Sabor \\
\hline Clorogénico & Amargo, astringente \\
\hline Quínico & Amargo, ácido \\
\hline Cítrico & Limón \\
\hline Acético & Agrio \\
\hline Málico & Manzana verde \\
\hline Fórmico & Acre \\
\hline Fosfórico & Ácido \\
\hline Glicólico & Ácido fuerte \\
\hline Láctico & Agridulce, leche \\
\hline Fumárico & Ácido, no picante \\
\hline Maléico & Irritante, acre \\
\hline Succí́nico & Amargo, salado \\
\hline Tartárico & Uvas negras \\
\hline
\end{tabular}

Fuente: Puerta (2011). 
Como se observa, las sensaciones de sabor enunciadas en la tabla anterior describen una bebida con una mezcla de sabores a ácido, amargo, dulce, cítrico, floral, frutal y madera, entre otros, con sensaciones al paladar que pueden ser descritas como astringente o residual.

De esta manera, al consumir una taza de café, gracias a la reacción de Maillard generada a una temperatura entre 150 y $200{ }^{\circ} \mathrm{C}$. Los grupos carbonilo de los carbohidratos y los amino de las proteínas reaccionan para formar compuestos aromáticos que le otorgan aroma al café (American Chemical Society, s.f.), incluyendo el 2-furfuriltiol (figura 3).

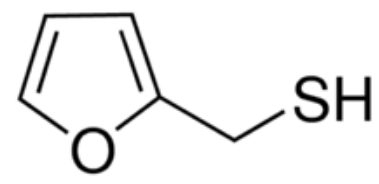

Figura 3. Estructura química 2-furfuriltiol

Por otro lado, a una temperatura entre 170 y $200^{\circ} \mathrm{C}$ los carbohidratos presentes en el grano se caramelizan produciendo algunos compuestos que proporcionan sabor y color al grano, entre otros diacetilos y furanonas (figura 4).
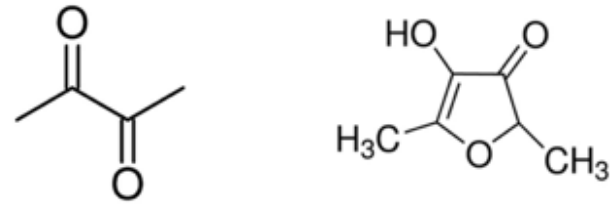

Diacetilo: proporciona sabor a caramelo

Furanonas: proporciona sabor azúcar quemado

Figura 4. Compuestos de caramelización

\section{Referencias}

American Chemical Society. (s.f.). Why Does Your Coffee Taste and Smell Delicious? Recuperado de https://www.acs.org/content/dam/acsorg/pressroom/reactions/infographics/coffee-beans-hr.jpg

Cenicafé. (s.f.). Quiénes Somos/ Historia. Recuperado de https://www.cenicafe.org/es/index.php/ quienes_somos/historia

Echeverri, D., Buitrago, L., Montes, F., Mejía, I., y González, M. (2005). Café para Cardiólogos. Revista Colombiana de Cardiología, XI(8), 357-365.

Lazcano, E., Trejo, M., Pascual, S., y Vargas, M. (2016). Efecto del grado de tostado en granos de café de diferentes regiones productoras de México sobre el contenido de compuestos fenólicos, cafeína y la actividad antioxidante. Investigación y Desarrollo en Ciencia y Tecnología de Alimentos, I(1), 478-483.

Pérez-Hérnandez, L., Chávez-Quiroz, K., Medina-Juárez, L., y Gámez-Meza, N. (2016). Compuestos fenólicos, melanoidinas y actividad antioxidante de café verde y procesado de las especies coffea arabica y coffea canephora. Revista de Ciencias Biológica y de la Salud, XV(1), 51-56.

Puerta, G. (2011). Composición química de una taza de café. Avances Técnicos, (414), 1-12.

Valencia, G., Rojas, M., y Beltrán, M. (2015). Armenia enclave exportador de café 1927-1959. Bogotá: Ministerio de Cultura de Colombia. 